Article

\section{The prognostic value of whole-blood PSMB5, CXCR4, POMP and RPL5 mRNA expression in patients with multiple myeloma treated with bortezomib}

\author{
Paweł Robak ${ }^{1}$, Dariusz Jarych ${ }^{2,3}$, Damian Mikulski' ${ }^{4}$, Izabela Dróżdż, Edyta Węgłowska ${ }^{2}$, \\ Aleksandra Kotkowska ${ }^{6}$, Małgorzata Misiewicz ${ }^{6}$, Piotr Smolewski ${ }^{1}$, Konrad Stawiski ${ }^{4}$, Wojciech \\ Fendler ${ }^{4}$, Janusz Szemraj ${ }^{7}$ and Tadeusz Robak ${ }^{6}$ \\ ${ }^{1}$ Department of Experimental Hematology, Medical University of Lodz, 93-510 Lodz, Poland; \\ pawel.robak@umed.lodz.pl (P.R.); piotr.smolewski@umed.lodz.pl (P.S.) \\ ${ }^{2}$ Laboratory of Personalized Medicine, Bionanopark, Lodz, 93-465 Lodz, Poland; \\ d.jarych@bionanopark.pl (D.J.); e.weglowska@bionanopark.pl (E.W.) \\ ${ }^{3}$ Laboratory of Virology, Institute of Medical Biology, Polish Academy of Sciences, Lodz, Poland; \\ djarych@cbm.pan.pl (D.J.) \\ ${ }^{4}$ Department of Biostatistics and Translational Medicine, Medical University of Lodz, 92-215 Lodz, Poland; \\ damian.mikulski@stud.umed.lodz.pl(D.M.); konrad.stawiski@stud.umed.lodz.pl (K.S.); \\ wojciech_fendler@dfci.harvard.edu (W.F.) \\ ${ }^{5}$ Department of Clinical Genetics, Medical University of Lodz, 92-213 Lodz, Poland; \\ izabela.drozdz@umed.lodz.pl (I.D.) \\ ${ }^{6}$ Department of Hematology, Medical University of Lodz, 93-510 Lodz, Poland; \\ robaktad@csk.umed.lodz.pl(T.R.);aleksandra.kotkowska@umed.lodz.pl (A.K.); \\ malgorzata.misiewicz@umed.lodz.pl (M.M.) \\ ${ }^{7}$ Department of Medical Biochemistry, Medical University of Lodz, 92-215 Lodz, Poland; \\ janusz.szemraj@umed.lodz.pl \\ * Correspondence: e-mail: robaktad@csk.umed.lodz.pl; tel: +48 42 689-51-91 ; fax:+ 4842 689-51-92
}

Simple Summary: The mRNA expression of nine previously-described genes that may affect resistance to multiple myeloma (MM), viz. ABCB1, CXCR4, MAF, MARCKS, POMP, PSMB5, RPL5, $T X N$ and $X B P 1$, was compared between bortezomib-refractory and bortezomib-sensitive patients. RPL5 was the only gene to be significantly down-regulated in MM patients compared with non-MM individuals, while $P O M P$ was significantly up-regulated in the bortezomib-refractory patients. Multivariate analysis found the best independent predictors of progression-free survival to be high PSMB5 and CXCR expression and autologous stem cell transplantation, and that high expression of POMP and RPL5 were associated with shorter survival.

\begin{abstract}
Proteasome inhibitors, like bortezomib, play a key role in the treatment of multiple myeloma (MM); however, most patients eventually relapse and eventually show multiple drug resistance, and the molecular mechanisms of this resistance remain unclear. The present study examines the expression of previously-described genes that may influence resistance to bortezomib treatment at the mRNA level (ABCB1, CXCR4, MAF, MARCKS, POMP, PSMB5, RPL5, TXN and $X B P 1)$. mRNA expression was determined in $73 \mathrm{MM}$ patients treated with bortezomib-based regimens (30 bortzomib-sensitive and 43 bortezomib-refractory patients) and 11 healthy controls. RPL5 was significantly down-regulated in multiple myeloma patients as compared with healthy controls. Moreover, POMP was significantly up-regulated in MM patients refractory to bortezomib-based treatment. In multivariate analysis, high expression of PSMB5 and CXCR and autologous stem cell transplantation were independent predictors of progression-free survival, and high expression of $P O M P$ and RPL5 was associated with shorter overall survival.
\end{abstract}


Keywords: ABCB1; bortezomib; CXCR4; gene expression; MAF; MARCKS; multiple myeloma; mRNA; POMP; PSMB5; refractory; RPL5; TXN; XBP1; sensitive

\section{Introduction}

Multiple myeloma (MM, plasma cell myeloma) is a hematological malignancy characterized by accumulation of malignant plasma cells $(\mathrm{PC})$ in the bone marrow $(\mathrm{BM})$, often resulting in bone lesions, hypercalcemia, infections, anemia, and production of monoclonal immunoglobulin [1]. The disease occurs mainly in older patients and accounts for $15 \%$ of all hematologic malignancies, with an annual incidence of 4.5-6 cases per 100,000 [2], with an estimated 32,270 new cases and 12,830 deaths in the USA in 2020 [3]. Proteasome inhibitors (PI) play a key role in the treatment of MM [4-6]. Three PIs, bortezomib, carfilzomib and ixazomib, are currently approved for the treatment of MM and several others are undergoing clinical trials [7].

Bortezomib is the first-in-class selective and reversible inhibitor of the $26 \mathrm{~S}$ proteasome. It demonstrates antiproliferative and antitumor activity, and its use has been a breakthrough in treating $\mathrm{MM}$ in the past 15 years [5]. It is a boronic acid-based compound, which inhibits $\beta 5$ chymotrypsin-like (CT-L) and to a lesser extent, $\beta 1$ caspase-like (C-L) of the proteasome; it has been approved for treatment both in front-line and in relapsed / refractory patients [7]. However the development of resistance and side effects can limit its use in MM [8]. Most patients show resistance to bortezomib after several courses of treatment and most of them demonstrate multiple drug resistance. In addition, approximately $20 \%$ of patients exhibit primary resistance, which determines lack of response to treatment $[8,9]$.

Although resistance to PIs appears to be acquired through a number of different mechanisms, genetic abnormalities play a key role for most anti-myeloma drugs [8,10-12]. Single-point mutations and modification of gene expression in neoplastic cells refractory to PI have been reported in previous studies [11,13-17]. Several genes associated with bortezomib resistance have been identified in MM cells, including POMP, XBP1, PSMB5, MARCKS, ABCB1, CXCR4, MAF, TXN, TJP1, RPL5, CDK5 and CYP1A1 [18-25]; however, these genes have been examined individually, and usually only using commercially-available MM cell lines. The present study comprehensively examines the mRNA expression of nine previously-described genes that may affect resistance in patients with a clinically-detected loss of response to PI treatment: ABCB1, CXCR4, MAF, MARCKS, POMP, PSMB5, RPL5, TXN and XBP1. A better understanding of the genetic disorders involved in $\mathrm{MM}$ drug resistance can improve prognosis and prognostication, assist the development of new therapeutic options, and progress the treatment of this disease.

\section{Results}

The demographic, clinical, and laboratory characteristics of the MM patients enrolled for the study are presented in Table 1. Overall, 30 of the 73 patients were bortezomib sensitive, while the other 43 were refractory. No statistically-significant differences were observed between bortezomib-sensitive and bortezomib-refractory MM patients with regard to bone involvement at diagnosis $(p=0.96)$, calcium $>2.75 \mathrm{mmol} / \mathrm{l}$ at diagnosis $(p=0.89)$, creatinine $>2 \mathrm{mg} / \mathrm{dl}$ at diagnosis $(p$ $=0.31)$ or $\mathrm{Hb}<10 \mathrm{~g} / \mathrm{dl}$ at diagnosis $(p=0.73)$ and ISS $(p=0.86)$. The only statistically-significant difference was observed in predominant paraprotein level $(p=0.02)$. In addition, light chain disease (LCD) was more common (36.7\%) among the sensitive group than the refractory group $(9.3 \%)$.

Table 1. The characteristics of the MM patients treated with bortezomib-based therapy and healthy donors. Data are presented as frequency, percentage (\%) unless otherwise specified.

\begin{tabular}{cccccc}
\hline Variable & MM total & Refractory & Sensitive & $\begin{array}{c}\text { Healthy } \\
\text { donors }\end{array}$ & $\mathbf{p}$ \\
\hline Number of patients & 73 & 43 & 30 & 11 & - \\
\hline Gender $(\%)$ & M:43 (58.9) & M: $25(58.1)$ & M: $18(60,0)$ & M: $5(45.5)$ & 0.69 \\
\hline
\end{tabular}




\begin{tabular}{|c|c|c|c|c|c|}
\hline $\mathrm{N}(\%)$ & F: 30 (41.1) & F: 18 (41.9) & F: $12(40,0)$ & F: $6(54.5)$ & \\
\hline Age + SD (range) & $\begin{array}{l}61.9 \pm 10.8 \\
(38.2-83.7)\end{array}$ & $\begin{array}{c}62.2 \pm 11.5 \\
(38.2-83.7)\end{array}$ & $\begin{array}{c}61.3 \pm 9.7 \\
(39.8- \\
81.6)\end{array}$ & $\begin{array}{l}63.0 \pm 6.2 \\
(52.6-74.4)\end{array}$ & 0.73 \\
\hline Bortezomib regimen: & & & & \multirow{6}{*}{-} & \multirow{6}{*}{0.18} \\
\hline VCD & $58(79.5)$ & $32(74.4)$ & $26(86.7)$ & & \\
\hline VMP & $6(8.2)$ & $5(11.6)$ & $1(3.3)$ & & \\
\hline VTD & $4(5.5)$ & $2(4.7)$ & $2(6.7)$ & & \\
\hline VD & $4(5.5)$ & $4(9.3)$ & 0 & & \\
\hline IsaVRD & $1(1.4)$ & 0 & $1(6.7)$ & & \\
\hline \multicolumn{6}{|l|}{ Paraprotein- N (\%) } \\
\hline $\operatorname{IgG}$ & $41(56.2)$ & $28(65.1)$ & $13(43.3)$ & \multirow{3}{*}{-} & \multirow{3}{*}{0.02} \\
\hline $\operatorname{IgA}$ & $17(23.3)$ & $11(25.6)$ & $6(20.0)$ & & \\
\hline LCD & $15(20.5)$ & $4(9.3)$ & $11(36.7)$ & & \\
\hline Prior treatment & $12(16.4)$ & $11(25.6)$ & $1(3.3)$ & & 0.01 \\
\hline Bone involvement at diagnosis & $40(54.8)$ & $23(53.5)$ & $17(56.6)$ & - & 0.96 \\
\hline Calcium $>2.75 \mathrm{mmol} / \mathrm{l}$ at diagnosis & $12(16.4)$ & $7(16.3)$ & $5(16.7)$ & - & 0.89 \\
\hline $\mathrm{HB}<10 \mathrm{~g} / \mathrm{dL}$ at diagnosis & $26(35.6)$ & $14(32.6)$ & $12(40.0)$ & - & 0.73 \\
\hline Creatinine $>2 \mathrm{mg} / \mathrm{dL}$ at diagnosis & $10(13.7)$ & $4(9.3)$ & $6(20.0)$ & - & 0.31 \\
\hline \multirow{3}{*}{$\begin{array}{c}\text { International Staging System (ISS) at } \\
\text { diagnosis }\end{array}$} & I: $22(30.1)$ & I: 14 (32.6) & I: $8(26.7)$ & \multirow{3}{*}{-} & \multirow{3}{*}{0.86} \\
\hline & II: 17 (23.3) & II: 10 (23.3) & II: 7 (23.3) & & \\
\hline & III:32(43.8) & III: $18(41.9)$ & III: $14(46.7)$ & & \\
\hline $\mathrm{CRP}>5 \mathrm{mg} / \mathrm{L}$ & $33(45.2)$ & $16(37.2)$ & $17(56.7)$ & - & 0.06 \\
\hline Beta2-microglobuline increased (> 3mg/L) & $51(69.9)$ & $31(72.1)$ & $20(66.7)$ & - & 0.36 \\
\hline $\mathrm{LDH}>240 \mathrm{U} / \mathrm{L}$ & $9(12.3)$ & $5(11.6)$ & $4(13.3)$ & - & 0.85 \\
\hline Cytogenetics- (\%) & $\mathrm{N}=41$ & $\mathrm{~N}=24$ & $\mathrm{~N}=17$ & & \\
\hline $\mathrm{t}(4 ; 14)$ & $9(22.0)$ & $7(29.2)$ & $2(11.8)$ & & 0.26 \\
\hline $\mathrm{t}(14 ; 16)$ & 0 & 0 & 0 & & - \\
\hline $\mathrm{t}(14 ; 20)$ & 0 & 0 & 0 & & - \\
\hline $\operatorname{del}(17 p)$ & $6(14.6)$ & $4(16.7)$ & $2(11.8)$ & & 1.00 \\
\hline $\operatorname{amp}(1 q)$ & $22(53.7)$ & $12(50.0)$ & $10(58.8)$ & & 0.75 \\
\hline $\operatorname{del}(13 q)$ & $8(19.5)$ & $2(8.3)$ & $6(35.3)$ & & 0.61 \\
\hline $\mathrm{t}(11 ; 14)$ & $1(2.4)$ & $1(4.2)$ & 0 & & 1.00 \\
\hline $\operatorname{del}(1 p)$ & $2(4.9)$ & $1(4.2)$ & $1(5.9)$ & & 1.00 \\
\hline IGH rearrangements & $19(46.3)$ & $12(50.0)$ & $7(41.2)$ & & 0.71 \\
\hline
\end{tabular}

Abbreviations: CRP- c-reactive protein; IGH - immunoglobulin heavy chain; LCD - light chain disease; IsaVRD - isatuximab, lenalidomide, bortezomib, dexamethasone; LDH - lactate dehydrogenase; MM - multiple myeloma; VCD - bortezomib, cyclophosphamide, dexamethasone; VD - bortezomib and dexamethasone: VMP - bortezomib, melphalan and prednisone; VTD bortezomib, thalidomide, dexamethasone

Twelve patients had received at least one prior therapy before bortezomib-based regimen initiation and 11 of them had become refractory to bortezomib. It was found that 41 patients displayed IgG paraprotein, 17 demonstrated IgA, and 15 had LCD. Most of the patients (79.5\%) had received a bortezomib, cyclophosphamide, and dexamethasone (VCD) regimen, six (8.2\%) VMP (bortezomib, melphalan, and prednisone), four (5.5\%) VTD (bortezomib, thalidomide, and dexamethasone), another four VD (bortezomib and dexamethasone), and one received IsaVRd (isatuximab, lenalidomide, bortezomib, and dexamethasone). Cytogenetics data was available in 41 patients (56.1\%). Amp (1q) was the most common abnormality (53.7\%), followed by IGH rearrangements $(46.3 \%), \mathrm{t}(4 ; 14)(22.0 \%)$ and $\operatorname{del}(13 q)(19.5 \%)$.

A flowchart depicting the number of patients in all stages of the study and reasons for exclusion are presented in Figure 1. The expression of nine mRNAs (ABCB1, CXCR4, MAF, MARCKS, POMP, PSMB5, RPL5, TXN and XBP1) was determined in all $73 \mathrm{MM}$ patients treated with bortezomib-based regimens and the 11 non-MM controls. Differential expression analysis indicated that RPL5 was 
significantly down-regulated in MM patients compared with controls (Table 2, Figure 2A). Moreover, POMP was significantly up-regulated in bortezomib-refractory MM patients (Table 3, Figure 2B). No statistically significant differences were found between the groups with regard to the expression of selected mRNAs and the quality of response to treatment (Table S1 and Table S2).

Table 2. mRNA expression in MM patients and healthy donors. The higher $\Delta \mathrm{Ct}$ value represents the lower expression of gene at mRNA level.

\begin{tabular}{|c|c|c|c|c|c|}
\hline mRNA & $\begin{array}{c}\Delta \mathrm{Ct} M M \\
(\mathrm{~N}=73) \\
\text { mean } \pm \mathrm{SD}\end{array}$ & $\begin{array}{c}\Delta \mathrm{Ct} \text { Healthy donors }(\mathrm{N}=11) \\
\text { mean } \pm \mathrm{SD}\end{array}$ & FC & $p$-value & FWER \\
\hline $\mathrm{ABCB} 1$ & $7.55 \pm 0.99$ & $7.12 \pm 0.74$ & 0.74 & 0.1075 & 0.6451 \\
\hline CXCR4 & $3.83 \pm 0.82$ & $3.56 \pm 0.21$ & 0.82 & 0.0209 & 0.1669 \\
\hline MAF & $7.75 \pm 1.08$ & $7.20 \pm 0.85$ & 0.68 & 0.0737 & 0.5159 \\
\hline MARCKS & $5.99 \pm 0.83$ & $5.63 \pm 0.90$ & 0.78 & 0.2346 & 1.0000 \\
\hline POMP & $5.17 \pm 0.67$ & $5.12 \pm 0.39$ & 0.97 & 0.7541 & 1.0000 \\
\hline PSMB5 & $6.96 \pm 0.78$ & $6.80 \pm 0.59$ & 0.90 & 0.4341 & 1.0000 \\
\hline RPL5 & $2.73 \pm 0.81$ & $2.02 \pm 0.46$ & 0.61 & 0.0004 & 0.0033 \\
\hline TXN & $3.43 \pm 0.74$ & $3.69 \pm 0.66$ & 1.20 & 0.2508 & 1.0000 \\
\hline XBP1 & $3.26 \pm 0.92$ & $3.21 \pm 0.66$ & 0.96 & 0.8036 & 1.0000 \\
\hline
\end{tabular}

Abbreviations: ABCB1 - Adenosine-triphosphate-binding cassette sub-family B member 1; CXCR-4 C-X-C chemokine receptor type 4; FWER - family-wise error rate: MAF - musculoaponeurotic fibrosarcoma; MARCKS - myristoylated alanine-rich C-kinase substrate; MM - multiple myeloma; POMP - proteasome maturation protein; PSMB5 - proteasome subunit $\beta$ type 5: RPL5 - ribosomal protein L5; TXN - thioredoxin; XBP1 - X-box binding protein 1

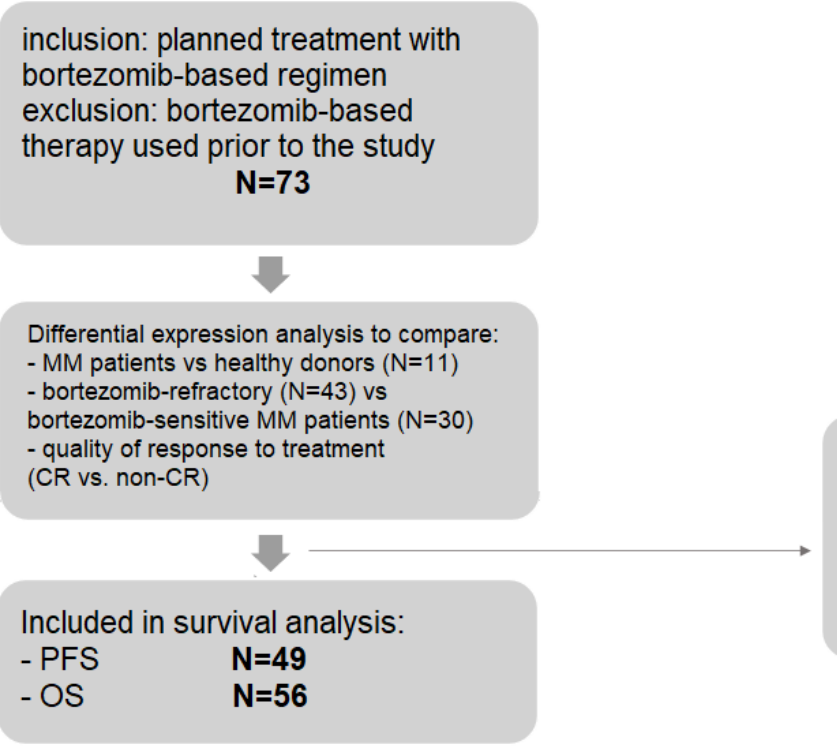

$\begin{array}{ll}\begin{array}{l}\text { Excluded: } \\ \text {-prior treatment }\end{array} & \mathrm{N}=12 \\ \text {-missing data: } & \\ \text { PFS } & \mathrm{N}=12 \\ \text { OS } & \mathrm{N}=5\end{array}$

Figure 1. Flow chart of study protocol and main analyses.

Abbreviations: CR- complete response; MM- multiple myeloma; OS- overall survival; PFSprogression-free survival 
A

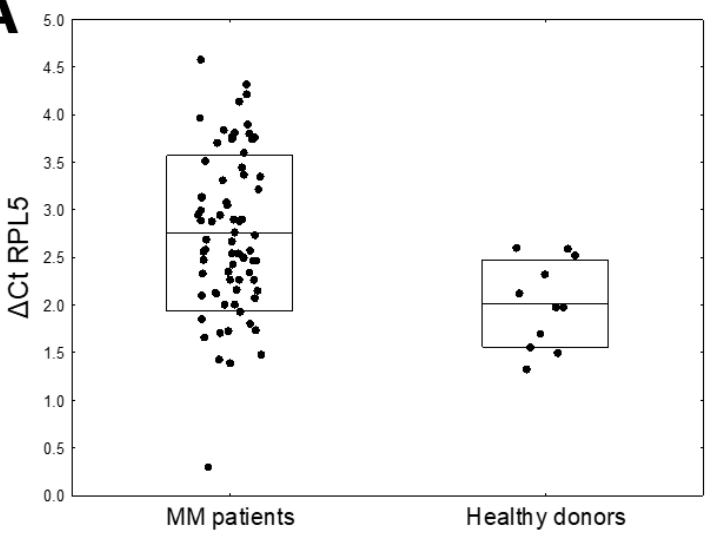

B

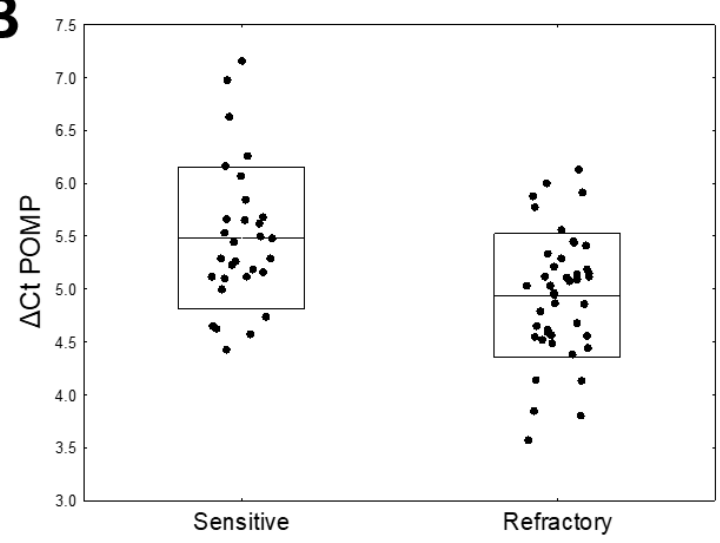

Figure 2. Dot plot representation of the $\Delta \mathrm{Ct}$ values of differentially expressed mRNA. The box plots depict the mean and SD. A higher $\triangle \mathrm{Ct}$ value represents the lower expression of the gene at the mRNA level: (A) $\triangle \mathrm{Ct}$ of RPL5 in multiple myeloma patients healthy donors ( $\mathrm{p}=0.0033$ ) and (B) $\Delta \mathrm{Ct}$ of $P O M P$ in sensitive and refractory to bortezomib MM patients (0.0062).

Table 3. mRNA expression in MM patients sensitive and refractory to bortezomib-based chemotherapy. The higher $\Delta \mathrm{Ct}$ value represents the lower expression of gene at mRNA level.

\begin{tabular}{cccccc}
\hline mRNA & $\begin{array}{c}\Delta \text { Ct Refractory }(\mathbf{N}=43) \\
\text { mean } \pm \text { SD }\end{array}$ & $\begin{array}{c}\Delta \text { Ct Sensitive }(\mathbf{N}=\mathbf{3 0}) \\
\text { mean } \pm \text { SD }\end{array}$ & FC & p-value & FWER \\
\hline ABCB1 & $7.58 \pm 1.02$ & $7.50 \pm 0.98$ & 0.95 & 0.7384 & 1.0000 \\
\hline CXCR4 & $3.75 \pm 0.70$ & $3.95 \pm 0.96$ & 1.15 & 0.3438 & 1.0000 \\
\hline MAF & $7.70 \pm 1.12$ & $7.82 \pm 1.03$ & 1.09 & 0.6516 & 1.0000 \\
\hline MARCKS & $5.79 \pm 0.70$ & $6.27 \pm 0.92$ & 1.40 & 0.0190 & 0.1522 \\
\hline POMP & $4.94 \pm 0.57$ & $5.48 \pm 0.67$ & 1.45 & 0.0007 & 0.0062 \\
\hline PSMB5 & $6.84 \pm 0.70$ & $7.12 \pm 0.87$ & 1.22 & 0.1421 & 0.8523 \\
\hline RPL5 & $2.69 \pm 0.87$ & $2.78 \pm 0.75$ & 1.06 & 0.6622 & 1.0000 \\
\hline TXN & $3.35 \pm 0.72$ & $3.55 \pm 0.77$ & 1.15 & 0.2676 & 1.0000 \\
\hline XBP1 & $3.08 \pm 0.84$ & $3.51 \pm 0.97$ & 1.35 & 0.0537 & 0.3759 \\
\hline
\end{tabular}

Abbreviations: ABCB1 - Adenosine-triphosphate-binding cassette sub-family B member 1; CXCR-4 C-X-C chemokine receptor type 4; FWER - family-wise error rate; MAF - musculoaponeurotic fibrosarcoma; MARCKS - myristoylated alanine-rich C-kinase substrate; MM - multiple myeloma; POMP - proteasome maturation protein; PSMB5 - proteasome subunit $\beta$ type 5: RPL5 - ribosomal protein L5; TXN - thioredoxin; XBP1 - X-box binding protein 1

To provide a unified assessment of the prognostic impact of selected mRNA expression level at diagnosis, twelve patients who had received prior treatment before the bortezomib-based regimen were excluded from the outcome analysis. In the course of multiple myeloma, the duration of response decreases consistently with each successive regimen [26]. In this way, previous treatment itself is a factor that severely impacts PFS. There were data on PFS available in 11/12 previously-treated patients, and the impact of this factor is presented in the Figure S1. On the other hand, in the previously treated group, there were no statistically significant differences in mRNAs expression (Table S3). Therefore in order to increase the statistical power of analysis this group was not excluded from differential expression analyses.

Overall, data on progression free survival (PFS) was available for 49 patients and data on overall survival (OS) for 56 patients. The median PFS was 14.4 months and the median OS was 29.0 months. Univariate Cox proportional hazards regression analysis was conducted to determine the prognostic value of the quantified mRNA expression; the results indicated that in MM patients, higher expression of CXCR4, MARCKS, POMP, PSMB5, TXN and XBP1 was significantly correlated with shorter PFS (Table 4, Figure 3). Univariate analysis found higher expression of POMP and RPL5 to be associated with shorter OS in MM patients (Figure 4). In addition, the only clinical variable 
which was related to PFS and OS was the use of autologous stem cell transplantation (ASCT) during the treatment schedule (Figure 5).

To check our PFS analyses' robustness, where there were 12 cases of missing data, we repeated our univariate Cox regressions with the replacement of 7 cases with OS time as it was available. It resulted in similar hazard ratios and p-values, and previously significant mRNAs maintained their significance (Table S4).

Table 4. Univariate Cox regression analyses for progression-free survival and overall survival.

\begin{tabular}{|c|c|c|c|c|c|c|c|c|c|c|}
\hline \multirow{3}{*}{ Variables } & \multicolumn{5}{|c|}{ PFS } & \multicolumn{5}{|c|}{ OS } \\
\hline & \multirow{2}{*}{$\begin{array}{c}\text { Coefficien } \\
t\end{array}$} & \multirow[b]{2}{*}{$\begin{array}{c}\text { p-valu } \\
\text { e }\end{array}$} & \multirow[b]{2}{*}{ HR } & \multicolumn{2}{|c|}{$95 \% \mathrm{CI}$} & \multirow[b]{2}{*}{$\begin{array}{c}\text { Coefficien } \\
\mathbf{t}\end{array}$} & \multirow[b]{2}{*}{$\begin{array}{c}\text { p-valu } \\
\text { e }\end{array}$} & \multirow[b]{2}{*}{ HR } & \multicolumn{2}{|c|}{$95 \% \mathrm{CI}$} \\
\hline & & & & $\begin{array}{c}\text { lowe } \\
\mathbf{r}\end{array}$ & $\begin{array}{c}\text { uppe } \\
\text { r }\end{array}$ & & & & $\begin{array}{c}\text { lowe } \\
\mathbf{r}\end{array}$ & $\begin{array}{c}\text { uppe } \\
\mathbf{r}\end{array}$ \\
\hline ABCB1 expression (high vs. low) & -0.248 & 0.2716 & $\begin{array}{c}0.60 \\
9\end{array}$ & $\begin{array}{c}0.25 \\
2\end{array}$ & 1.474 & -0.226 & 0.2950 & $\begin{array}{c}0.63 \\
7\end{array}$ & $\begin{array}{c}0.27 \\
3\end{array}$ & 1.482 \\
\hline CXCR4 expression (high vs. low) & 0.571 & $\mathbf{0 . 0 3 2 7}$ & $\begin{array}{c}3.13 \\
4 \\
\end{array}$ & $\begin{array}{c}1.09 \\
9\end{array}$ & 8.940 & 0.272 & 0.2865 & $\begin{array}{c}1.72 \\
2 \\
\end{array}$ & $\begin{array}{c}0.63 \\
4 \\
\end{array}$ & 4.679 \\
\hline MAF expression (high vs. low) & 0.261 & 0.1348 & $\begin{array}{c}1.68 \\
5 \\
\end{array}$ & $\begin{array}{c}0.85 \\
0 \\
\end{array}$ & 3.336 & 0.390 & 0.2968 & $\begin{array}{c}2.18 \\
3 \\
\end{array}$ & $\begin{array}{c}0.50 \\
4 \\
\end{array}$ & 9.464 \\
\hline $\begin{array}{l}\text { MARCKS expression (high vs. } \\
\text { low) }\end{array}$ & 0.594 & 0.0018 & $\begin{array}{c}3.28 \\
1\end{array}$ & $\begin{array}{c}1.55 \\
9\end{array}$ & 6.907 & -0.343 & 0.1115 & $\begin{array}{c}0.50 \\
4\end{array}$ & $\begin{array}{c}0.21 \\
7\end{array}$ & 1.172 \\
\hline POMP expression (high vs. low) & 0.409 & 0.0236 & $\begin{array}{c}2.26 \\
6 \\
\end{array}$ & $\begin{array}{c}1.11 \\
6 \\
\end{array}$ & 4.601 & 0.573 & 0.0108 & $\begin{array}{c}3.14 \\
4 \\
\end{array}$ & $\begin{array}{c}1.30 \\
3 \\
\end{array}$ & $\mathbf{7 . 5 8 5}$ \\
\hline PSMB5 expression (high vs. low) & 0.476 & 0.0088 & $\begin{array}{c}2.59 \\
1\end{array}$ & $\begin{array}{c}1.27 \\
1\end{array}$ & 5.280 & 0.348 & 0.1497 & $\begin{array}{c}2.00 \\
4\end{array}$ & $\begin{array}{c}0.77 \\
8\end{array}$ & 5.158 \\
\hline RPL5 expression (high vs. low) & -0.137 & 0.4206 & $\begin{array}{c}0.76 \\
0\end{array}$ & $\begin{array}{c}0.38 \\
9\end{array}$ & 1.483 & 0.641 & 0.0035 & $\begin{array}{c}3.60 \\
7\end{array}$ & $\begin{array}{c}1.52 \\
6\end{array}$ & 8.524 \\
\hline TXN expression (high vs. low) & 0.394 & 0.0290 & $\begin{array}{c}2.19 \\
8 \\
\end{array}$ & $\begin{array}{c}1.08 \\
4 \\
\end{array}$ & 4.456 & 0.298 & 0.1683 & $\begin{array}{c}1.81 \\
3 \\
\end{array}$ & $\begin{array}{c}0.77 \\
8 \\
\end{array}$ & 4.228 \\
\hline XBP1 expression (high vs. low) & 0.479 & 0.0099 & $\begin{array}{c}2.60 \\
5 \\
\end{array}$ & $\begin{array}{c}1.25 \\
9 \\
\end{array}$ & 5.389 & 0.270 & 0.2091 & $\begin{array}{c}1.71 \\
5 \\
\end{array}$ & $\begin{array}{c}0.73 \\
9 \\
\end{array}$ & 3.981 \\
\hline Age & 0.006 & 0.7070 & $\begin{array}{c}1.00 \\
6 \\
\end{array}$ & $\begin{array}{c}0.97 \\
5 \\
\end{array}$ & 1.038 & 0.037 & 0.1281 & $\begin{array}{c}1.03 \\
8 \\
\end{array}$ & $\begin{array}{c}0.98 \\
9 \\
\end{array}$ & 1.089 \\
\hline $\begin{array}{l}\text { ASCT } \\
\text { No } \\
\text { Yes }\end{array}$ & $\begin{array}{c}\text { Reference } \\
-\mathbf{0 . 4 8 7}\end{array}$ & 0.0089 & $\begin{array}{c}0.37 \\
8 \\
\end{array}$ & $\begin{array}{c}0.18 \\
2 \\
\end{array}$ & 0.783 & $\begin{array}{c}\text { Reference } \\
-\mathbf{0 . 6 2 4}\end{array}$ & 0.0157 & $\begin{array}{c}0.28 \\
7 \\
\end{array}$ & $\begin{array}{c}0.10 \\
4 \\
\end{array}$ & 0.790 \\
\hline $\begin{array}{c}\text { Bone involvement at diagnosis } \\
\text { No } \\
\text { Yes }\end{array}$ & $\begin{array}{c}\text { Reference } \\
0.303\end{array}$ & 0.1043 & $\begin{array}{c}1.83 \\
2 \\
\end{array}$ & $\begin{array}{c}0.88 \\
2 \\
\end{array}$ & 3.805 & $\begin{array}{c}\text { Reference } \\
0.309\end{array}$ & 0.1932 & $\begin{array}{c}1.85 \\
6 \\
\end{array}$ & $\begin{array}{c}0.73 \\
1 \\
\end{array}$ & 4.709 \\
\hline $\begin{array}{c}\text { Calcium }>2,75 \mathrm{mmol} / \mathrm{l} \text { at } \\
\text { diagnosis } \\
\text { No } \\
\text { Yes }\end{array}$ & $\begin{array}{c}\text { Reference } \\
0.374\end{array}$ & 0.0929 & $\begin{array}{c}2.11 \\
2 \\
\end{array}$ & $\begin{array}{c}0.88 \\
3 \\
\end{array}$ & 5.052 & $\begin{array}{c}\text { Reference } \\
-0.089\end{array}$ & 0.7501 & $\begin{array}{c}0.83 \\
7 \\
\end{array}$ & $\begin{array}{c}0.28 \\
1 \\
\end{array}$ & 2.495 \\
\hline $\begin{array}{c}\mathrm{CRP}>5 \mathrm{mg} / \mathrm{L} \\
\text { No } \\
\text { Yes }\end{array}$ & $\begin{array}{c}\text { Reference } \\
0.101\end{array}$ & 0.6100 & $\begin{array}{c}1.22 \\
4 \\
\end{array}$ & $\begin{array}{c}0.56 \\
3 \\
\end{array}$ & 2.663 & $\begin{array}{c}\text { Reference } \\
-0.461\end{array}$ & 0.0637 & $\begin{array}{c}0.39 \\
8 \\
\end{array}$ & $\begin{array}{c}0.15 \\
0 \\
\end{array}$ & 1.054 \\
\hline $\begin{array}{c}\mathrm{HB}<10 \mathrm{~g} / \mathrm{dL} \text { at diagnosis } \\
\text { No } \\
\text { Yes }\end{array}$ & $\begin{array}{c}\text { Reference } \\
0.092\end{array}$ & 0.6243 & $\begin{array}{c}1.20 \\
2 \\
\end{array}$ & $\begin{array}{c}0.57 \\
6 \\
\end{array}$ & 2.505 & $\begin{array}{c}\text { Reference } \\
0.009\end{array}$ & 0.9698 & $\begin{array}{c}1.01 \\
8 \\
\end{array}$ & $\begin{array}{c}0.40 \\
9 \\
\end{array}$ & 2.530 \\
\hline $\begin{array}{c}\text { ISS I } \\
\text { ISS II } \\
\text { ISS III }\end{array}$ & $\begin{array}{c}\text { Reference } \\
-0.682 \\
0.383\end{array}$ & $\begin{array}{l}0.0590 \\
0.1594\end{array}$ & $\begin{array}{c}0.37 \\
5 \\
1.08 \\
9 \\
\end{array}$ & $\begin{array}{c}0.12 \\
4 \\
0.50 \\
9 \\
\end{array}$ & $\begin{array}{l}1.134 \\
2.326\end{array}$ & $\begin{array}{c}\text { Reference } \\
0.030 \\
0.544\end{array}$ & $\begin{array}{l}0.9389 \\
0.0684\end{array}$ & $\begin{array}{c}1.82 \\
8 \\
3.05 \\
6 \\
\end{array}$ & $\begin{array}{c}0.46 \\
0 \\
1.03 \\
5 \\
\end{array}$ & $\begin{array}{l}7.267 \\
9.021\end{array}$ \\
\hline $\begin{array}{c}\text { Creatinine }>2 \mathrm{mg} / \mathrm{dL} \text { at diagnosis } \\
\text { No } \\
\text { Yes }\end{array}$ & $\begin{array}{c}\text { Reference } \\
-0.396\end{array}$ & 0.1952 & $\begin{array}{c}0.45 \\
3 \\
\end{array}$ & $\begin{array}{c}0.13 \\
6 \\
\end{array}$ & 1.502 & $\begin{array}{c}\text { Reference } \\
-0.253\end{array}$ & 0.4984 & $\begin{array}{c}0.60 \\
3 \\
\end{array}$ & $\begin{array}{c}0.14 \\
0 \\
\end{array}$ & 2.606 \\
\hline $\begin{array}{c}\mathrm{LDH}>240 \mathrm{U} / \mathrm{L} \\
\text { No } \\
\text { Yes }\end{array}$ & $\begin{array}{c}\text { Reference } \\
0.188\end{array}$ & 0.4221 & $\begin{array}{c}1.45 \\
7 \\
\end{array}$ & $\begin{array}{c}0.58 \\
1 \\
\end{array}$ & 3.651 & $\begin{array}{c}\text { Reference } \\
0.411\end{array}$ & 0.1526 & $\begin{array}{c}2.27 \\
7 \\
\end{array}$ & $\begin{array}{c}0.73 \\
7 \\
\end{array}$ & 7.032 \\
\hline $\begin{array}{c}\text { Gender } \\
\text { F } \\
\text { M }\end{array}$ & $\begin{array}{c}\text { Reference } \\
-0.287\end{array}$ & 0.1008 & $\begin{array}{c}0.56 \\
4\end{array}$ & $\begin{array}{c}0.28 \\
4\end{array}$ & 1.118 & $\begin{array}{c}\text { Reference } \\
0.352\end{array}$ & 0.1583 & $\begin{array}{c}2.02 \\
2 \\
\end{array}$ & $\begin{array}{c}0.76 \\
0 \\
\end{array}$ & 5.376 \\
\hline
\end{tabular}


Abbreviations: ABCB1 - Adenosine-triphosphate-binding cassette sub-family B member 1; ASCT - autologous stem cel transplantation; CRP- c-reactive protein; CXCR-4 - C-X-C chemokine receptor type 4; FWER - family-wise error rate: HB - hemoglobin; ISS - International scoring system; MAF - musculoaponeurotic fibrosarcoma; LDH - lactate dehydrogenase; MARCKS - myristoylated alanine-rich C-kinase substrate; MM - multiple myeloma; OS - overall survival; PFS - progression free survival; POMP - proteasome maturation protein; PSMB5 - proteasome subunit $\beta$ type 5: RPL5 - ribosomal protein L5; TXN - thioredoxin; XBP1 - X-box binding protein 1
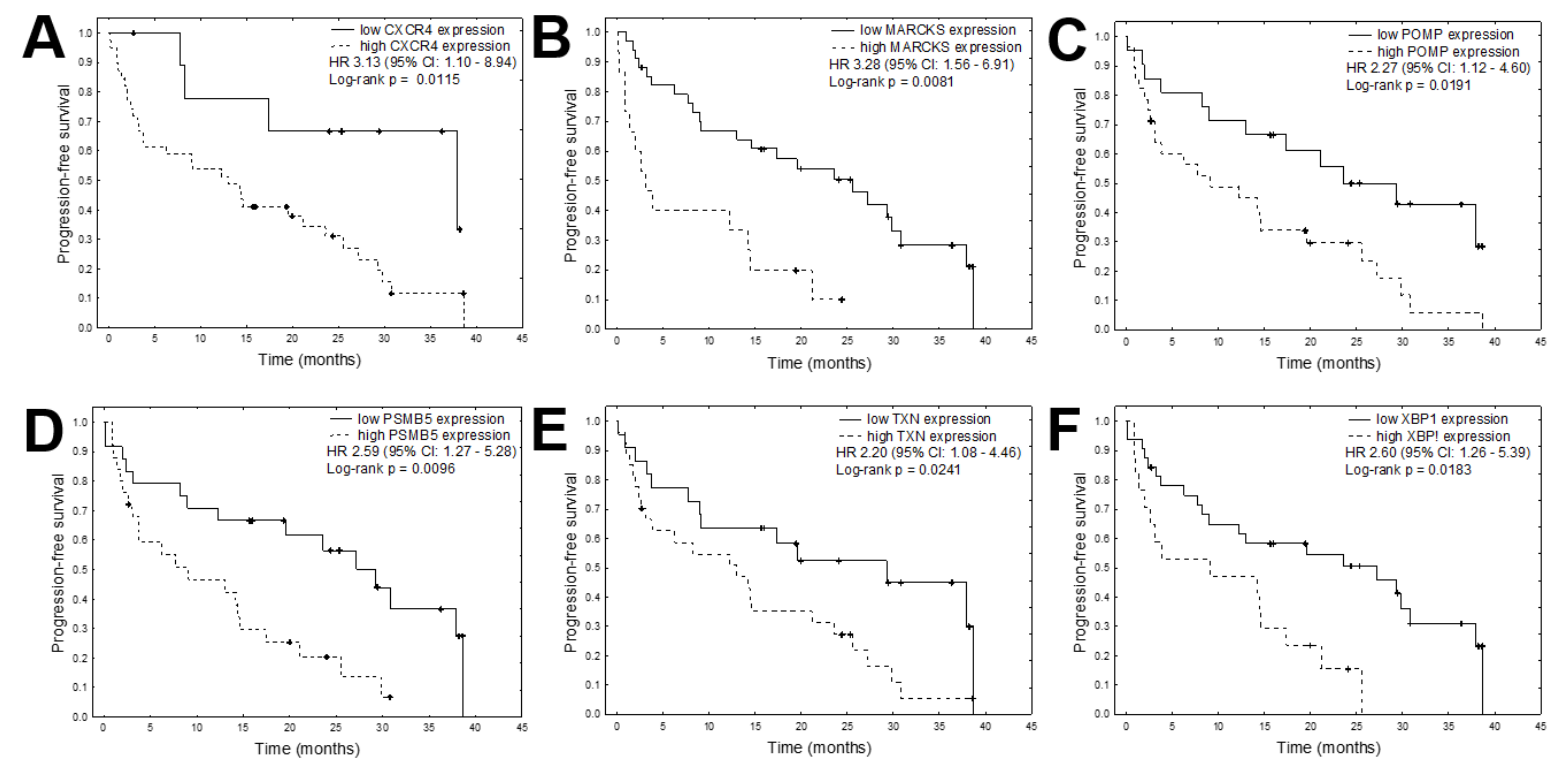

Figure 3. Kaplan-Meier plots for each of the significant mRNAs in the univariate analyses for PFS: (A) CXCR4, (B) MARCKS, (C) POMP, (D) PSMB5, (E) TXN, (F) XBP1.
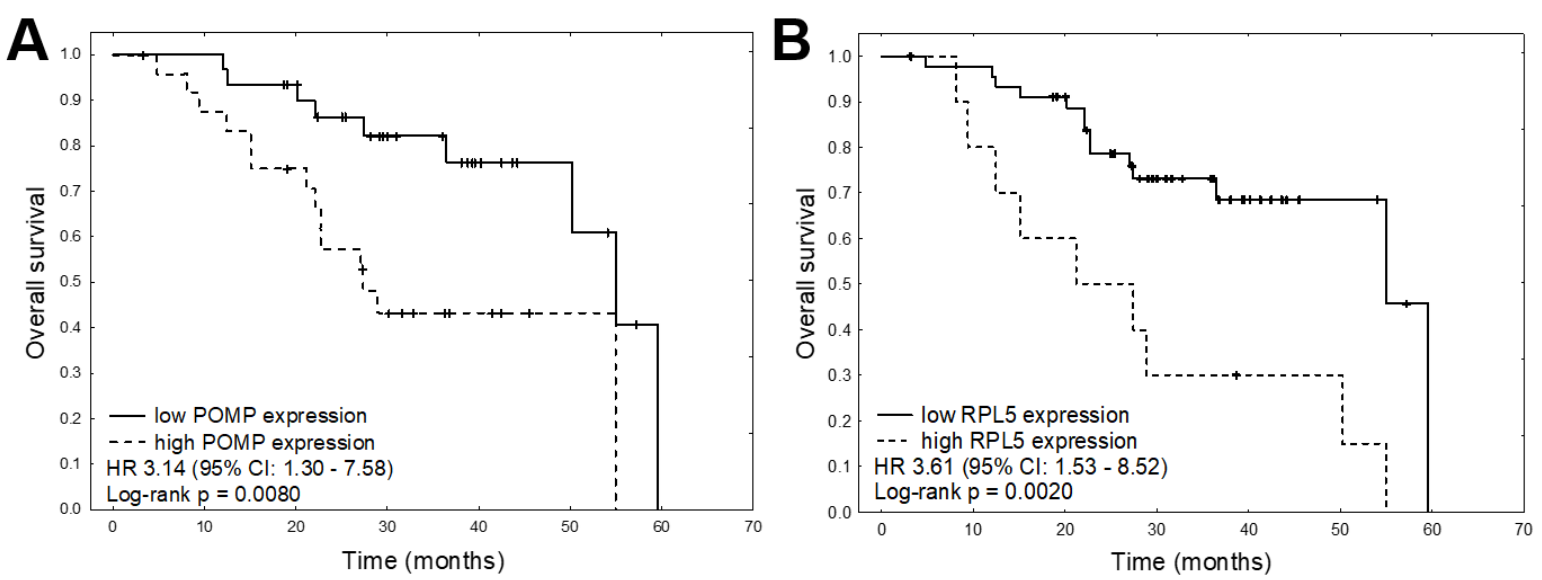

Figure 4. Kaplan-Meier plots for each of the significant mRNAs in the univariate analyses for OS: (A) POMP, (B) RPL5. 

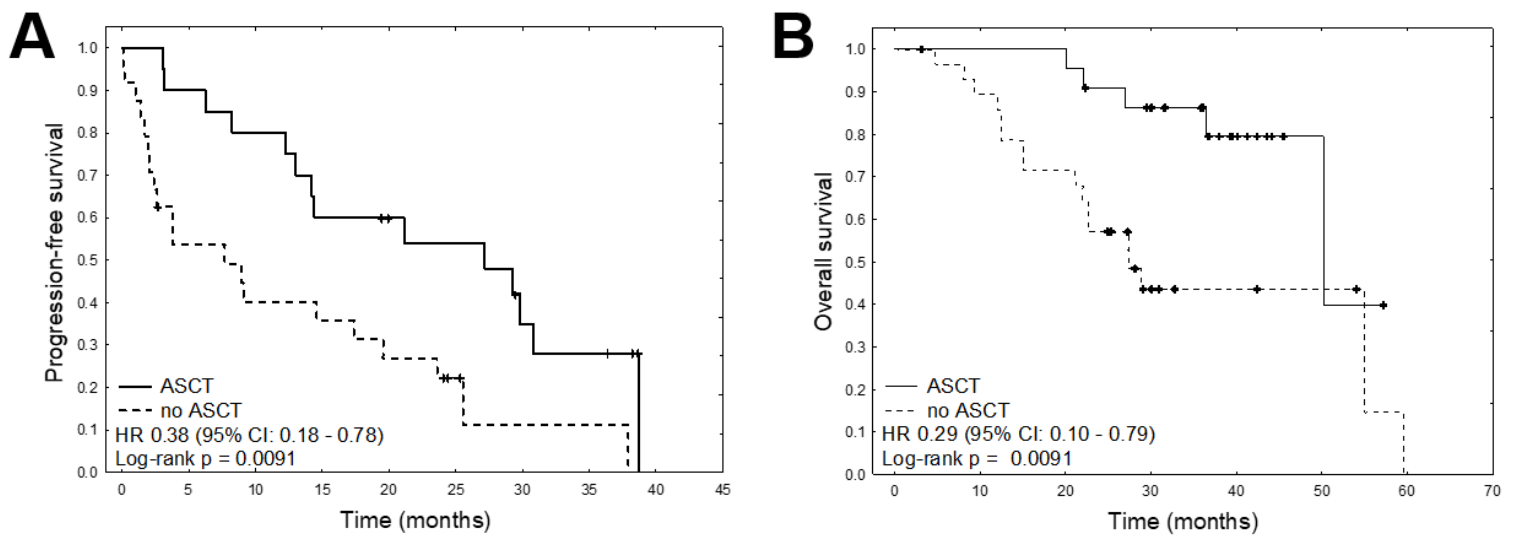

Figure 5. Kaplan-Meier plots for ASCT in the univariate analyses for (A) PFS and (B) OS.

To further investigate the prognostic factors, multivariate analyses were carried out using Cox's proportional hazards regression model with a stepwise selection procedure. As ASCT was the only significant clinical variable in our univariate analyses with proven prognostic significance, it was entered as covariate in the multivariable model. The results found high expression of PSMB5 and CXCR and the presence of ASCT to be the best independent predictors of PFS (Table 5). Multivariate analysis of OS found high expression of POMP and RPL5 to be associated with shorter survival.

We repeated our analyses with mRNAs expression as continuous variables- Table S5. In the univariate analyses, PSMB5 and CXCR4 lost their significance. In the next step, the multivariate proportional hazards regression model with a stepwise selection procedure was performed (Model 2, Table S6). An approach based on dichotomized variables yielded a model with better fit to the data with a lower AIC value.

Table 5. Final multivariate Cox regression analyses for PFS and OS of MM patients.

\begin{tabular}{cccccc}
\hline & \multicolumn{5}{c}{ PFS } \\
Variables & Coefficient & p-value & HR & \multicolumn{2}{c}{ 95\% CI } \\
& & & & lower & upper \\
PSMB5 expression (high vs. low) & 0.386 & 0.0451 & 2.164 & 1.017 & 4.603 \\
CXCR expression (high vs. low) & 0.748 & 0.0073 & 4.465 & 1.496 & 13.320 \\
ASCT & & & & & \\
No & Reference & \multicolumn{4}{c}{0} \\
Yes & -0.612 & 0.0024 & 0.294 & 0.133 & 0.649 \\
Variables & \multicolumn{5}{c}{ OS } \\
POMP expression (high vs. low) & 0.523 & 0.0258 & 2.849 & 1.135 & 7.148 \\
RPL5 expression (high vs. low) & 0.664 & 0.0026 & 3.777 & 1.591 & 8.963 \\
\hline
\end{tabular}

Abbreviations: ASCT - autologous stem cell transplantation; CXCR-4 - C-X-C chemokine receptor type 4; HR - hazard ratio; MM - multiple myeloma; OS - overall survival; PFS - progression free survival; POMP - proteasome maturation protein; PSMB5 - proteasome subunit $\beta$ type 5: RPL5 ribosomal protein L5; XBP1 - X-box binding protein 1

\section{Discussion}

The study comprehensively determined the mRNA expression of nine genes that may affect resistance in $73 \mathrm{MM}$ patients treated with bortezomib-based regimens and 11 healthy volunteers: ABCB1, CXCR4, MAF, MARCKS, POMP, PSMB5, RPL5, TXN and XBP1. The genes were selected on 
the basis of previous laboratory and clinical studies investigating the bortezomib resistance in MM patients [19-21,27]. In our study we have chosen the gene expression evaluation on whole-blood samples, as it is easier to use in clinical practice than the method with a preliminary PC isolation. Standardization of mRNA expression profiling after cytometric isolation of specific population of cells may be technically challenging due to the variability of material quality, cell numbers and other factors important at this scale of experiments (cell cycle, mutation profile, clonicity etc.). Moreover, designing a model based only on a selected population of cells could downplay the interactions between the cells and the immunologic system or other unforeseeable effects. Restricting ourselves to a cell subset would therefore potentially result in a potentially, very accurate test if cells are isolated correctly, but not sufficiently robust to use in different settings, with different technical tools and in varying clinical scenarios. Functional analysis of these genes changing their activity within the cells during different phases of treatment would be an exciting study, but one that would likely require a different experimental model, cell cultures and in depth mechanistic evaluations far exceeding the scope of this survival-oriented analysis. A similar method but based only on leukocytes in peripheral blood, not whole blood, was recently used by Watanabe et al. in evaluating novel biomarkers to predict bortezomib response in MM patients [28].

According to the differential expression analysis, RPL5 gene was the only gene that was significantly down-regulated in MM patients compared with normal individuals; however, higher RPL5 expression correlated with shorter survival in MM patients. RPL5 has also been found to be deleted in $20-40 \%$ of MM patients, and it is the only recurrently-mutated ribosomal protein gene in MM $[29,30]$.

In addition, RPL5 mRNA expression level was proposed as a clinical biomarker for response to bortezomib in MM patients: Hofman et al. reported significantly lower RPL5 mRNA expression in patients with MM who initially responded to bortezomib and then relapsed, and both newly-diagnosed and relapsed patients with low RPL5 expression had better PFS when bortezomib was used in their treatment. In addition, they reported an association between low RPL5 mRNA levels and initial response to bortezomib in relapsed MM patients. RPL5 expression has also been associated with shorter survival in newly-diagnosed patients [30].

In our study, $P O M P$ gene was significantly up-regulated in MM patients refractory to bortezomib-based treatment in comparison with bortezomib-sensitive patients. Higher expression of POMP was found to be associated with shorter survival: POMP protein expression is essential for the biogenesis of proteasome de novo and its increased expression facilitates acquired resistance to PI [17]. An increase in POMP protein expression has also been noted in V10R, RPMI 8226, OPM-2, ANBL-6 and KAS-6/1 MM cells resistant to bortezomib [17,31]. Similarly to the present study, POMP protein suppression via shRNAs restored cell sensitivity, while over-expression favored resistance.

A protein-binding site for a suppressive factor, NRF2, has also been identified in the promoter region of the POMP protein. Although its increased expression should increase sensitivity to bortezomib, expression of POMP has been found to be increased in resistant cells, together with increased levels of POMP protein. The activation of both proteins varies according to cell line, and POMP appeared to have a greater effect on bortezomib sensitivity in the KAS-6/1 than OPM-2 line [32].

In the MM patients in the present study, univariate Cox proportional hazards regression analysis found the expression of six of the nine studies genes, viz. PSMB5, CXCR4, MARCKS, POMP, $T X N$ and XBP1, to significantly correlate with PFS. In addition, the multivariate analysis found high expression of PSMB5, CXCR and ASCT to be the best independent predictors of PFS. Proteasome subunit $\beta$ type 5 (PSMB5) is the target for bortezomib and other PI inhibitors that harbor chymotrypsin-like proteolytic activity [33]. Bortezomib occupies the PSMB5 substrate binding pocket, interfering with the catalytic N-terminal threonine residue. Apart from $\beta 5$ point mutations, the most frequent change observed in the bortezomib-resistant cell lines was overexpression of the 
$\beta 5$ subunit [22,34-35]. A recent study by Barrio et al. identified somatic PSMB5 substitutions in an MM patient treated with bortezomib, suggesting that resistance acquired through PSMB5 point mutations is clinically relevant [23]. Recently, in KMS-18 and KMS-27 MM cells, the PSMB5 gene was found to harbor novel bortezomib resistance alleles which determine response to second-generation proteasome inhibitors in MM [37]. In addition, PSMB5 deletion resensitized drug-resistant, PSMB5-mutated cell lines to bortezomib, suggesting that PSMB5 mutation plays a role in drug resistance [38].

Our findings indicated that higher CXCR4 expression correlated with shorter PFS. CXCR4 is a pleiotropic chemokine receptor which acts through its ligand (CXCL12) and influences proliferation, invasion, dissemination and drug resistance in MM [39,40]. The current therapeutic focus is on disrupting the interaction of MM cells with their protective tumor microenvironment, in which the CXCR4 axis plays an essential role [41]. In contrast to our present study, reduced expression of CXCR4, a single biomarker in the Bcl-XL/Myc model system, has indicated poorer outcomes in MM patients treated with bortezomib [42]. In addition, low CXCR4 expression was associated with a worse outcome than high CXCR4 expression, and correlated with increased MM severity and aggressiveness in patients treated with bortezomib, either alone or in combination with other agents $[20,42]$.

The univariate Cox proportional hazards regression analysis found the that higher expression of MARCKS, TXN and XBP1 significantly correlated with shorter PFS in MM patients. Another marker of PI resistance is MARCKS. This protein is important in cell adhesion and metastatic spread [43] and is involved in resistance to apoptosis in prostate cancer cells [17]. Its expression is significantly elevated in many types of cancer [44]. Micallef et al. reported overexpression of MARCKS in nine of 18 (50\%) studied MM cell lines [45]; in addition, in line with our present findings, Yang et al. reported increased MARCKS expression in bortezomib-refractory MM patients, as well as increased bortezomib sensitivity in bortezomib- resistant MM cells following inhibition of MARCKS phosphorylation [46]. Similar effects were achieved in an MM xenograft model [47].

A key role in bortezomib resistance is played by the increased expression of proteasomes and proteins involved in protection from oxidative stress, such as thioredoxin (TXN) [48]. Our findings indicate that higher expression of TXN correlates with shorter PFS. Previous studies have also found TXN to be overexpressed in primary myeloma cells isolated from bortezomib-resistant MM patients, and that overexpression of TXN correlated with poor overall survival in patients with MM [48]. In bortezomib-resistant myeloma cell lines, TXN inhibition overcomes adaptive bortezomib resistance [49]. In addition, higher TXN1 expression levels were found to correlate with myeloma cell survival and growth, and to protect MM cells against increased intrinsic oxidative stress [50]. Moreover, inhibition of TXN1 leads to apoptosis in drug-resistant MM.

Another gene whose high expression significantly correlated with shorter PFS in MM patients is $\mathrm{XBP} 1$, coding for $\mathrm{X}$-box binding protein 1 . The $\mathrm{XBP1}$ protein is an important transcription factor necessary for differentiation of $B$ cells into plasma cells, being responsible for the final maturation of plasmablasts to plasmocytes and the induction of immunoglobulin secretion [51]. XBP1 is also a particularly important regulator in the UPR mechanism. It is spliced into two isoforms. One isoform, XBPs1s, activates the genes necessary to reduce ER stress and UPR activation after penetration into the cell nucleus. XBP1 may have a significant impact on resistance to bortezomib in MM cells. Low expression of XBPS1 has been associated with a lack of sensitivity to PI treatment [52]. Two point mutations in the XBP1 gene have been identified to date [51,53]: the first, XBP1-L167I, is located within the splice site of the XBP1 gene, and has been shown to prevent the XBP1 mRNA splicing process needed to form the active XBP1s protein, while the second, XBP1s-P326R, is located within the transactivation domain of the XBP1s molecule and has no effect on the splicing process. Cells displaying one of the described mutations lose their sensitivity to bortezomib, inducing disease resistance [54].

In conclusion, our results suggest that high expression of PSMB5 and CXCR may serve as predictors of PFS in MM patients treated with bortezomib based regimens. In addition, high expression of POMP and RPL5 can be useful to predict shorter survival of these patients. However, 
further studies are needed to determine the role of this factors in effective strategy for improving anti-myeloma therapy.

\section{Materials and Methods}

\subsection{Patients.}

The patients were recruited prospectively in our institution (Department of Hematology, Copernicus Memorial Hospital, Lodz, Poland) as a part of a planned marker study. The main exclusion criterion was bortezomib-based therapy used prior to the study. The main inclusion criteria were diagnosis of multiple myeloma according to International Myeloma Working Group (IMWG) criteria and planned treatment with bortezomib-based regimen [55]. A total of $73 \mathrm{MM}$ patients (43 men and 30 women) treated were included. The mean age of the group was $61.9 \pm$ 10.8 years (range: 38.2 to 83.7 years). Their demographic, clinical and laboratory details are shown in Table 1. All of the patients received bortezomib treatment as first-line treatment or in progression after previous therapy. The participants were classified as either bortezomib-sensitive or bortezomib-refractory, as previously reported, according to their response to bortezomib-based therapy $[12,56]$. Response to treatment and relapse/progression events were classified according to the IMWG $[57,58]$.

The bortezomib-sensitive patients demonstrated CR, VGPR or PR lasting longer than six months following discontinuation of bortezomib-based therapies [58-60]. In total, 30 patients were bortezomib refractory and 43 were bortezomib sensitive with no progression for at least six months of treatment discontinuation. The control group consisted of 11 healthy volunteers (six women and five men; mean age $61.9 \pm 10.8$ years; range: $38.2-83.7$ years). The study was conducted according to good clinical and laboratory practice.

All procedures were approved by the local ethical committee (The Ethical Committee of the Medical University of Lodz, No RNN/103/16/KE). All patients and controls enrolled in the study gave written informed consent for all examinations and procedures. The experimental protocol was conducted in accordance with the Declaration of Helsinki.

\subsection{Blood collection}

Peripheral blood was taken from the 73 multiple myeloma patients and 11 healthy volunteers and collected to the PAXgene Blood RNA Tubes (Qiagen) and stored frozen at $-80{ }^{\circ} \mathrm{C}$. Venous blood samples were collected from MM patients, before treatment with bortezomib-based regimens, most commonly on the first day of the bortezomib administration. In previously treated MM patients, blood was collected at the time of progression, during the qualification process for commencement of new therapy line.

\subsection{The analysis of gene expression using real-time PCR}

\subsubsection{Isolation of total RNA}

Frozen blood samples were thawed on ice and total RNA was isolated from $1.5 \mathrm{ml}$ of blood using the QIAamp RNA Blood Mini Kit (Qiagen) according to the manufacturer's protocol. The final elution of total RNA was performed using $50 \mu \mathrm{l}$ of RNase-free water. Total RNA quality was determined using the High Sensitivity RNA Screen Tape on a 2200 TapeStation bioanalyzer (Agilent). The degradation rate of RNA were determined using RNA integrity number (RIN). Only the samples with RIN $>7$ were further analyzed. The quantity of RNA was measured using NanoVue Plus Spectrophotometer (GE Healthcare). Directly after isolation, RNA was used for the reverse transcription process.

\subsubsection{Reverse transcription reaction}


The reverse transcription was performed using the High-Capacity cDNA Reverse Transcription Kit (ThermoFisher Scientific), according to the manufacturer's protocol. The total volume of reverse transcription mix was $20 \mu \mathrm{L}$ per reaction, containing $2 \mu \mathrm{L}$ RT buffer (10X), 0,8 $\mu \mathrm{L}$ dNTP mixture (100 $\mathrm{mM}$ of each dNTP), $2 \mu \mathrm{L}$ random primers (10X), $1 \mu \mathrm{L}$ RNase inhibitor $(20 \mathrm{U} / \mu \mathrm{L}), 1 \mu \mathrm{L}$ MultiScribe Reverse Transcriptase (50 U/ $\mu \mathrm{L})$, and $10 \mu \mathrm{L}$ RNA template, whereby the reagent mix was prepared on ice. The thermal profile of the reverse transcription program consisted of 10 min incubation at 25 ${ }^{\circ} \mathrm{C}, 120 \mathrm{~min}$ at $37^{\circ} \mathrm{C}, 5 \mathrm{~min}$ reverse transcriptase inactivation at $85^{\circ} \mathrm{C}$, and cooling down to $4{ }^{\circ} \mathrm{C}$. Total amount of $100 \mathrm{ng}$ of RNA was used as a sample input per $20 \mu \mathrm{l}$ of reverse transcription reaction. All reactions were performed in a 96-well SureCycler 8800 thermal cycler (Agilent). The resulting cDNA was stored at $-20^{\circ} \mathrm{C}$.

\subsubsection{Selection of reference genes}

A reference gene provides the internal control of the reaction and allow to determine the absolute and reliable value of the studied gene expression using real-time PCR. In order to normalize for variations in sample input for relative quantitation of gene expression, the selection of endogenous control genes was performed using the TaqMan ${ }^{\mathrm{TM}}$ Array Human Endogenous Control (Thermo Fisher Scientific). The analysis was performed for six total RNA samples isolated from whole blood of MM patients, according to the manufacturer'sprotocol.

The stability of mRNAs was measured by NormiRazor [61]. This is an integrative tool which implements existing normalization algorithms (geNorm, NormFinder and BestKeeper) in a parallel manner. Three reference genes were selected by NormiRazor and TaqMan ${ }^{\mathrm{TM}}$ probes were purchased from ThermoFisher Scientific company: ACTB (Assay ID: Hs99999903_m1), RPLP0 (Assay ID: Hs99999902_m1), MT-ATP6 (Assay ID: Hs02596862_g1) and their average expression was used as reference.

\subsubsection{Real-time PCR}

The expression of nine genes was analysed in all samples: $A B C B 1, C X C R 4, M A F, M A R C K S$, POMP , PSMB5, RPL5, TXN and XBP1. The analysis was performed using commercially-available ready-to-use TaqMan ${ }^{\circledR}$ Assays (Thermo Fisher Scientific). These were preloaded with a probe labeled with 6-FAM ${ }^{\mathrm{TM}}$ dye (emission spectra at $\sim 517 \mathrm{~nm}$ ) and forward and reverse primers for the amplification of the following genes: ABCB1 (Assay ID: Hs00184500_m1), CXCR4 (Assay ID: Hs00976734_m1), MAF (Assay ID: Hs00193519_m1), MARCKS (Assay ID: Hs00158993_m1), POMP (Assay ID: Hs01106088_m1), PSMB5 (Assay ID: Hs00605652_m1, RPL5 (Assay ID: Hs00851991_u1), TXN (Hs00828652_m1), XBP1 (Assay ID: Hs00231936_ml).

The PCR mixture consisted of $10 \mu \mathrm{l}$ of 2X TaqMan ${ }^{\mathrm{TM}}$ Genotyping Master Mix (Thermo Fisher Scientific), $1 \mu \mathrm{l}$ of appropriate 20X TaqMan® Assay and $1 \mu \mathrm{l}$ of cDNA template. The mixture was filled up with a distilled, DNase and RNase free water (Gibco) to a final volume of $20 \mu \mathrm{l}$. The analysis was carried out using the TOptical thermal cycler (Biometra). The reactions were performed under the following conditions: an initial denaturation step at $95{ }^{\circ} \mathrm{C}$ for $10 \mathrm{~min}$, followed by 40 amplification cycles of denaturation $\left(95^{\circ} \mathrm{C}, 15 \mathrm{sec}\right)$, a single annealing and extension step $\left(60^{\circ} \mathrm{C}\right.$ for 1 minute). Fluorescence signal detection was performed after each cycle. Gene expression analysis was performed for each sample in duplicates.. Absolute quantification analysis was performed using qPCR Soft 3.1.15.0 (Biometra).

\subsection{Statistical analysis}

\subsubsection{Data preparation}

The data was normalized based on the mean expression of three mRNAs in a given sample (ACTB, RPLP0, MT-ATP6); this has proved to be the most stable normalization factor (according to NormiRazor). The normalized Ct values were calculated as :

Normalized $\Delta \mathrm{Ct}=\mathrm{Ct}$ mRNA - (mean Ct of ACTB, RPLP0 and MT-ATP6)

Normalized $\Delta \mathrm{Ct}$ values for all samples and with class assignments were provided as Table S7. 


\subsubsection{Analysis}

Nominal variables were expressed as percentages and analyzed using the Chi-square test with appropriate corrections if needed: the Yates correction for continuity or Fisher's exact test.

For continuous variables, normally-distributed data was tested using a two-sided independent Student's t-test. Continuous variables were presented as mean \pm standard deviation (SD) or medians with $25 \%$ to $75 \%$ values according to the data distribution. Survival analysis was conducted using a Kaplan-Meier estimate with univariate and multivariate Cox's proportional hazards models, as well as the log-rank test. Cutoff Finder was used to determine the optimal cutpoint for gene expression dichotomization based on the log-rank test minimum $P$-value approach [62]. Stratification of a continuous biomarker variable into two groups seems most natural for translation into clinics where most of the decisions are binary. Although the mean or median value of the diagnostic factor is commonly used, it is often desirable to determine cutoff points based on the variable's distribution or by optimizing the correlation with response to a treatment or outcome. The common problem in biomarker research is overestimating the actual effect when multiple cutoff points are investigated with no correction for multiple testing. Cutoff Finder's advantage is an investigation of particular cutoff points' robustness with estimation of effect size with confidence intervals [62].

All statistical analyses were conducted using Statistica Version 13.1 (TIBCO, Palo Alto, CA, USA) and $\mathrm{R}$ programming language (version 4.0.2). $\mathrm{P}$ values lower than 0.05 were considered statistically significant. To control the family-wise error rate (FWER), the significant genes were chosen at $5 \%$ using Holm's step-down method. FWER was used to insure a low probability of any false positives among differentially-expressed mRNA.

\section{Conclusions}

The present study examined the mRNA expression of nine genes with a possible influence on bortezomib sensitivity and refractoriness in MM, viz. ABCB1, CXCR4, MAF, MARCKS, POMP, PSMB5, RPL5, TXN and XBP1. Of these RPL5 was down-regulated in MM patients as compared with normal individuals. $P O M P$ was significantly up-regulated in $M M$ patients refractory to bortezomib-based treatment. Multivariate analysis found that high expression of PSMB5 and CXCR and autologous stem cell transplantation were the best independent predictors of PFS, and that high expression of POMP and RPL5 were associated with shorter survival. The clinical and biological importance of these findings need further investigation.

Supplementary Materials: The following supplementary tables are available online: Supplementary Table S1: $A B C B 1, C X C R 4, M A F, M A R C K S, P O M P, P S M B 5, R P L 5, T X N$ and XBP1 mRNA expression in MM patients with complete remission (CR) to bortezomib-based chemotherapy and those without. Supplementary Table S2: $A B C B 1, C X C R 4, M A F, M A R C K S, P O M P, P S M B 5, R P L 5, T X N$ and XBP1 mRNA expression in MM patients with at least very good partial response (VGPR), partial response, stable disease or disease progression $(<\mathrm{VGPR})$ after bortezomib-based treatment. No difference was found between the two groups. Supplementary Table S3: mRNA expression in MM patients treatment-naive and previously treated. The higher $\Delta \mathrm{Ct}$ value represents the lower expression of gene at mRNA level. Supplementary Table S4: Univariate Cox regression analyses for progression-free survival with missing data $(n=7)$ replaced by overall survival. Supplementary Table S5: Univariate Cox regression analyses for progression-free survival and overall survival- mRNAs expression as continuous variables. Supplementary Table S6: Comparison of final Cox regression of multivariate models based on dichotomized variables (model 1) and continuous variables (model 2). Supplementary Table S7: Normalized $\Delta$ Ct of mRNA expression for all samples and with class assignments. Supplementary Figure S1: S1. Kaplan-Meier plots for previous treatment and treatment-naïve groups in the univariate analysis for PFS.

Author Contributions: P.R., D.J. E.W. and I.D. performed the experiments; D.M., K.S. and W.F. performed statistical analyses; P.R., I.D., D.M. and T.R. designed the study and wrote the paper. P.R., I.D., D.J., D.M., A.K., M.S., M.M., K.S., W.F., J.S., P.S. and T.R. examined the available material, reviewed and revised the manuscript and provided their approval of the final version of the manuscript. All authors agree to be accountable for all aspects of the work.

Funding: This work was supported by a grant from the NCN (2016/23/B/NZ5/02529). 
Acknowledgments: We thank Edward Lowczowski from the Medical University of Lodz for editorial assistance and Andrzej Berut from Bionanopark, Lodz for administrative support.

Conflict of interest: The authors declare no conflict of interest. The funders had no role in the design of the study; in the collection, analyses, or interpretation of data; in the writing of the manuscript, or in the decision to publish the results.

\section{Abbreviations}

ABCB1 - Adenosine-triphosphate-binding cassette sub-family B member 1

ACTB - beta-actin gene

ASCT - autologous stem cell transplantation

$\mathrm{BM}$ - bone marrow

CXCR-4 - C-X-C chemokine receptor type 4

DLBCL - diffuse large B-cell lymphoma

ECM - extracellular matrix

FWER - family-wise error rate

IPO8 - Importin 8 gene

IsaRVD - isatuximab, lenalidomide, bortezomib, dexamethasone

MAF - musculoaponeurotic fibrosarcoma

MARCKS - myristoylated alanine-rich C-kinase substrate

MM - multiple myeloma

MT-ATP6 - mitochondrially Encoded ATP Synthase Membrane Subunit 6 gene

NRF2 - nuclear factor erythroid 2-related factor 2

NF- $\kappa \mathrm{B}$ - nuclear factor kappa B

OS - overall survival

PC - plasma cells

POMP - proteasome maturation protein

PFS - progression free survival

PI - proteasome inhibitor

PSMB5 - proteasome subunit $\beta$ type 5

RPLP0 - Ribosomal Protein Lateral Stalk Subunit P0 gene

RPL5 - ribosomal protein L5

UPR - unfolded protein response

TXN - thioredoxin

VCD - bortezomib, cyclophosphamide, dexamethasone

VD -bortezomib and dexamethasone

VMP - bortezomib, melphalan and prednisone.

VTD -bortezomib, thalidomide, dexamethasone

TXN - thioredoxin

XBP1 - X-box binding protein 1

\section{References}

1. International Myeloma Working Group. Criteria for the classification of monoclonal gammopathies, multiple myeloma and related disorders: a report of the International Myeloma Working Group. $\mathrm{Br} \mathrm{J}$ Haematol. 2003, 121, 749-57.

2. Palumbo A, Anderson K. Multiple Myeloma. N Engl J Med. 2011,364,1046-1060.

3. Siegel RL, Miller KD, Jemal A. Cancer statistics, 2020. CA Cancer J Clin. 2020, 70, 7-30.

4. Gandolfi S, Laubach JP, Hideshima T, Chauhan D, Anderson KC, Richardson PG. Cancer Metastasis Rev. 2017,36,561-584.

5. Robak P, Robak T. Bortezomib for the treatment of hematologic malignancies: 15 years later. Drugs $R$ D. 2019,19,73-92 
6. Mofers A, Selvaraju K, Gubat J, D'Arcy P, Linder S. Identification of proteasome inhibitors using analysis of gene expression profiles. Eur J Pharmacol. 2020:173709. doi: 10.1016/j.ejphar.2020.173709.

7. Okazuka K, Ishida T. Jpn J Clin Oncol. 2018;48:785-793.

8. Robak P, Drozdz I, Szemraj J, Robak T. Drug resistance in multiple myeloma. Cancer Treat Rev. 2018,70,199-208

9. San Miguel JF, Schlag R, Khuageva NK et al. Bortezomib plus melphalan and prednisone for initial treatment of multiple myeloma. N Engl J Med. 2008;359:906-917.

10. Lu S, Yang J, Chen $\mathrm{Z}$ et al. Different mutants of PSMB5 confer varying bortezomib resistance in T lymphoblastic lymphoma/leukemia cells derived from the Jurkat cell line. Exp. Hematol. 2009, 37,831-837.

11. Lu S, Yang J, Song X, Gong S et al. Point mutation of the proteasome beta5 subunit gene is an important mechanism of bortezomib resistance in bortezomib-selected variants of Jurkat $\mathrm{T}$ cell lymphoblastic lymphoma/leukemia line. J Pharmacol Exp Ther. 2008,326,423-431.

12. Robak P, Dróżdż I, Jarych D, Mikulski D, Węgłowska E, Siemieniuk-Ryś M, Misiewicz M, Stawiski K, Fendler $\mathrm{W}$, Szemraj J et al. The value of serum microRNA expression signature in predicting refractoriness to bortezomib-based therapy in multiple myeloma patients. Cancers (Basel). 2020,12,E2569.

13. Lü S, Yang J, Chen Z, Gong S, Zhou H, Xu X, Wang J. Different mutants of PSMB5 confer varying bortezomib resistance in $\mathrm{T}$ lymphoblastic lymphoma/leukemia cells derived from the Jurkat cell line. Exp. Hematol. 2009,37,831-837.

14. Brünnert D, Kraus M, Stühmer T, Kirner S, Heiden R, Goyal P, Driessen C, Bargou RC, Chatterjee M. Novel cell line models to study mechanisms and overcoming strategies of proteasome inhibitor resistance in multiple myeloma. Biochim Biophys Acta Mol Basis Dis. 2019 pii: S0925-4439(19)30114-0.

15. Barrio S, Stühmer T, Da-Viá M, Barrio-Garcia C, Lehners N, Besse A, Cuenca I, Garitano-Trojaola A, Fink $\mathrm{S}$, Leich E, et al. Spectrum and functional validation of PSMB5 mutations in multiple myeloma. Leukemia. 2019,33,447-456.

16. Ikeda H, Ishiguro K, Igarashi T, Aoki Y, Hayashi T, Ishida T, Sasaki Y, Tokino T, Shinomura Y. Molecular diagnostics of a single drug-resistant multiple myeloma case using targeted next-generation sequencing. Onco Targets Ther. 2015,8,2805-2815.

17. Niewerth D, Jansen G, Assaraf YG, Zweegman S, Kaspers GJ, Cloos J. Molecular basis of resistance to proteasome inhibitors in hematological malignancies. Drug Resist Updat. 2015,18,18-35.

18. Hawley TS, Riz I, Yang W, Wakabayashi Y, Depalma L, Chang YTet al.Identificationof an ABCB1 (P-glycoprotein)-positive carfilzomib-resistant myeloma subpopula-tion by the pluripotent stem cellfluorescent dye CDy1.Am J Hematol. 2013,88,265-272,

19. Besse A, Stolze SC, Rasche L, Weinhold N, Morgan GJ, Kraus M, Bader J, Overkleeft HS, Besse L, Driessen C. Carfilzomib resistance due to ABCB1/MDR1 overexpression is overcome by nelfinavir and lopinavir in multiple myeloma. Leukemia. 2018,32,391-401.

20. Mulligan G, Mitsiades C, Bryant B, Zhan F, Chng WJ, Roels S, Koenig E, Fergus A, Huang Y, Richardson $\mathrm{P}$,et al. Gene expression profiling and correlation with outcome in clinical trials of the proteasomeinhibitor bortezomib. Blood 2007,109, 3177-3188.

21. Nian F, Zhu J, Chang H. Long non-coding RNA ANGPTL1-3 promotes multiple myeloma bortezomib resistance by sponging miR-30a-3p to activate c-Maf expression. Biochem Biophys Res Commun. 2019;514:1140-1146

22. Oerlemans R, Franke NE, Assaraf YG, Cloos J, van Zantwijk I, Berkers CR, Scheffer GL, Debipersad K, Vojtekova K, Lemos C, et al. Molecular basis of bortezomib resistance: proteasome subunit beta5 (PSMB5) gene mutation and overexpression of PSMB5 protein. Blood. 2008,112,2489-2499.

23. Barrio S, Stühmer T, Da-Viá M, Barrio-Garcia C, Lehners N, Besse A, Cuenca I, Garitano-Trojaola A, Fink $\mathrm{S}$, Leich E, et al. Spectrum and functional validation of PSMB5 mutations in multiple myeloma. Leukemia. 2019;33:447-56.

24. Tang H, Xu L, Cen X, Yang L, Feng J, Li G, Zhu H, Gao S, Yu Y, Zhao Y, et al. CDK5 inhibition in vitro and in vivo induces cell death in myeloma and overcomes the obstacle of bortezomib resistance. Int J Mol Med. 2020;45:1661-1672. doi:10.3892/ijmm.2020.4553

25. Xu D, Hu J, De Bruyne E, Menu E, Schots R, Vanderkerken K,et al. Dll1/Notch activation contributes to bortezomib resistance by upregulating CYP1A1 in multiple myeloma. Biochem Biophys Res Commun. $2012,428,518-524$ 
26. Kumar SK, Therneau TM, Gertz MA, Lacy MQ, Dispenzieri A, Rajkumar SV, Fonseca R, Witzig TE, Lust JA, Larson DR, Kyle RA, Greipp PR. Clinical course of patients with relapsed multiple myeloma. Mayo Clin Proc. 2004 Jul;79(7):867-74.

27. Hawley TS, Riz I, Yang W, Wakabayashi Y, Depalma L, Chang YT, Peng W, Zhu J, Hawley RG. Identificationof an ABCB1 (P-glycoprotein)-positive carfilzomib-resistant myeloma subpopula-tion by the pluripotent stem cellfluorescent dye CDy1. Am J Hematol. 2013,88,265-272.

28. Watanabe T, Mitsuhashi M, Sagawa M, et al. Lipopolysaccharide-Induced CXCL10 mRNA Level and Six Stimulant-mRNA Combinations in Whole Blood: Novel Biomarkers for Bortezomib Responses Obtained from a Prospective Multicenter Trial for Patients with Multiple Myeloma. PLoS One. 2015 Jun 26;10(6):e0128662.

29. Lohr JG, Stojanov P, Carter SL, Cruz-Gordillo P, Lawrence MS, Auclair D, Sougnez C, Knoechel B, Gould J, Saksena G, et al. Widespread Genetic Heterogeneity in Multiple Myeloma: Implications for targeted therapy. Cancer Cell. 2014,25,91-101,

30. Hofman IJF, Patchett S, van Duin M, Geerdens E, Verbeeck J, Michaux L, Delforge M, Sonneveld P, Johnson AW, De Keersmaecker K. Low frequency mutations in ribosomal proteins RPL10 and RPL5 in multiple myeloma. Haematologica. 2017,102,e317-e320.

31. Li B, Wang H, Orlowski RZ. Proteasome maturation protein POMP is associated with proteasome inhibitor resistance in myeloma, and its suppression enhances the activity of bortezomib and carfilzomib. American Society of Hematology Annual Meeting Abstracts. Blood 2013;122 (Supplement 1): Abstract 280.

32. Li B, Fu J, Chen P, Ge X, Li Y, Kuiatse I, Wang H, Wang H, Zhang X, Orlowski RZ. The nuclear factor (Erythroid-derived 2)-like 2 and proteasome maturation protein axis mediate bortezomib resistance in multiple myeloma. J Biol Chem. 2015,290,29854-29868.

33. Unno M, Mizushima T, Morimoto Y, Tomisugi Y, Tanaka K,Yasuoka N, et al. The structure of the mammalian 20S proteasome at 2.75 A resolution. Structure. 2002,10,609-18.

34. Balsas P, Galan-Malo P, Marzo I, Naval J. 2012. Bortezomib resistance in a myeloma cell line is associated to PSM _5 overexpression and polyploidy. Leuk. Res. 36, 212-218.

35. Kuhn DJ, Berkova Z, Jones RJ, Woessner R, Bjorklund CC, Ma W, Davis RE, Lin P, Wang H, Madden TL, et al. Targeting the insulin-like growth factor-1 receptor to overcome bortezomib resistance in preclinical models of multiple myeloma. Blood. 2012,120,3260-3270

36. Verbrugge SE, Assaraf YG, Dijkmans BA, Scheffer GL, Al M, den Uyl D, Oerlemans R, Chan ET, Kirk CJ, Peters GJ, et al. Inactivating PSMB5 mutations and P-glycoprotein (multidrug resistance-associated protein/ATP-binding cassette B1) mediate resistance to proteasome inhibitors: ex vivo efficacy of (immuno)proteasome inhibitors in mononuclear blood cells from patients with rheumatoid arthritis. J Pharmacol Exp Ther. 2012,341,174-182.

37. Allmeroth K, Horn M, Kroef V, Miethe S, Müller RU, Denzel MS. Bortezomib resistance mutations in PSMB5 determine response to second-generation proteasome inhibitors in multiple myeloma. Leukemia. 2020 Jul 20. doi: 10.1038/s41375-020-0989-4.

38. Shi CX, Zhu YX, Bruins LA, Bonolo de Campos C, Stewart W, Braggio E, Stewart AK. Proteasome subunits differentially control myeloma cell viability and proteasome inhibitor sensitivity. Mol Cancer Res. 2020,18,1453-1464.

39. Ullah TR. The role of CXCR4 in multiple myeloma: Cells' journey from bone marrow to beyond. J Bone Oncol. 2019,17,100253.

40. Stessman HA, Mansoor A, Zhan F, Janz S, Linden MA, Baughn LB, Van Ness B. Reduced CXCR4 expression is associated with extramedullary disease in a mouse model of myeloma and predicts poor survival in multiple myeloma patients treated with bortezomib. Leukemia. 2013,27,2075-2077.

41. Shaughnessy JD Jr, Qu P, Usmani S, Heuck CJ, Zhang Q, Zhou Y, Tian E, Hanamura I, van Rhee F, Anaissie E,et al. Pharmacogenomics of bortezomib test-dosing identifies hyperexpression ofproteasome genes, especially PSMD4, as novel high-risk feature in myelomatreated with total therapy. Blood 2011,118,3512-3524.

42. Finlayson AE, Freeman KW. A cell motility screen reveals role for MARCKS-related protein in adherens junction formation and tumorigenesis. PLOS ONE 2009,4,e7833.

43. Li T, Li D, Sha J, Sun P, Huang Y. MicroRNA-21 directly targets MARCKS and promotes apoptosis resistance and invasion in prostate cancer cells. Biochem Biophys Res Commun. 2009, 383, 280-285. 
44. Niewerth D, Jansen G, Riethoff LF, van Meerloo J, Kale AJ, Moore BS, Assaraf YG, Anderl JL, Zweegman S, Kaspers GJ, et al. Antileukemic activity and mechanism of drug resistance to the marine Salinispora tropica proteasome inhibitor salinosporamide (Marizomib). Mol Pharmacol. 2014,86,12-19.

45. Micallef J, Taccone M, Mukherjee J, Croul S, Busby J, Moran MF, Guha A.Epidermal growth factor receptor variant III-induced glioma invasion is mediated through myristoylated alanine-rich protein kinase C substrate over-expression. Cancer Res. 2009,69,7548-56.

46. Wang J, Hendrix A, Hernot S, Lemaire M, De Bruyne E, Van Valckenborgh E, Lahoutte T, De Wever O, Vanderkerken K, Menu E. Bone marrow stromal cell-derived exosomes as communicators in drug resistance in multiple myeloma cells. Blood 2014,124, 555-66.

47. Yang Y, Chen Y, Saha MN, Chen J, Evans K, Qiu L, Reece D, Chen GA, Chang H.Targeting phospho-MARCKS overcomes drug resistance and induces antitumor activity in preclinical models of multiple myeloma. 2015,29,715-26.

48. Dytfeld D, Luczak M, Wrobel T, Usnarska-Zubkiewicz L, Brzezniakiewicz K, Jamroziak K, Giannopoulos K, Przybylowicz-Chalecka A, Ratajczak B, Czerwinska-Rybak J. Comparative proteomic profiling of refractory/relapsed multiple myeloma reveals biomarkers involved in resistance to bortezomib-based therapy. Oncotarget. 2016,7,56726-56736.

49. Zheng Z, Fan S, Zheng J, Huang W, Gasparetto C, Chao NJ, Hu J, Kang Y. Inhibition of thioredoxin activates mitophagy and overcomes adaptive bortezomib resistance in multiple myeloma. J Hematol Oncol. 2018, 27,11:29.

50. Raninga PV, Di Trapani G, Vuckovic S, Bhatia M, Tonissen KF. Inhibition of thioredoxin 1 leads to apoptosis in drug-resistant multiple myeloma. Oncotarget. 20,6,15410-15424.

51. Leung-Hagesteijn C, Erdmann N, Cheung G, et al. Xbp1s-negative tumor B cells and pre-plasmablasts mediate therapeutic proteasome inhibitor resistance in multiple myeloma. Cancer Cell. 2013,24,289-304

52. Liu N, Liu C, Li X, Liao S, Song W, Yang C, Zhao C, Huang H, Guan L, Zhang P,et al. A novel proteasome inhibitor suppresses tumor growth via targeting both 19S proteasome deubiquitinases and 20S proteolytic peptidases. Sci Rep. 2014,4,5240.

53. Hong SY, Hagen T. Multiple myeloma Leu167Ile (c.499C >A) mutation prevents XBP1 mRNA splicing. Br J Haematol. 2013;161:898-901.

54. Nikesitch N, Silvia C, Ling W. Molecular mechanisms in multiple myeloma drug resistance. J Clin Pathol. 2016,69,97-101.

55. Rajkumar SV, Dimopoulos MA, Palumbo A, Blade J, Merlini G, Mateos MV, Kumar S, Hillengass J, Kastritis E, Richardson P, Landgren O, Paiva B, Dispenzieri A, Weiss B, LeLeu X, Zweegman S, Lonial S, Rosinol L, Zamagni E, Jagannath S, Sezer O, Kristinsson SY, Caers J, Usmani SZ, Lahuerta JJ, Johnsen HE, Beksac M, Cavo M, Goldschmidt H, Terpos E, Kyle RA, Anderson KC, Durie BG, Miguel JF. International Myeloma Working Group updated criteria for the diagnosis of multiple myeloma. Lancet Oncol. 2014 Nov;15(12):e538-48.

56. Robak P, Węgłowska E, Dróżdż I, Mikulski D, Jarych D, Ferlińska M, Wawrzyniak E, Misiewicz M, Smolewski P, Fendler W, et al. Cytokine and chemokine profile in patients with multiple myeloma treated with bortezomib. Mediators Inflamm. 2020,2020,1835836

57. Durie BG, Harousseau JL, Miguel JS, Bladé J, Barlogie B, Anderson K, Gertz M, Dimopoulos M, Westin J, Sonneveld $\mathrm{P}$, et al. International uniform response criteria for multiple myeloma. Leukemia 2006,20,1467-1473.

58. Kyle RA, Rajkumar SV. Criteria for diagnosis, staging, risk stratification and response assessment of multiple myeloma. Leukemia 2009,23,3-9.

59. Anderson KC, Kyle RA, Rajkumar SV, Stewart AK, Weber D, Richardson P; ASH/FDA Panel on Clinical Endpoints in Multiple Myeloma. Clinically relevant end points and new drug approvals for myeloma. Leukemia. 2008,22,231-239.

60. Laubach JP, Mitsiades CS, Mahindra A, Luskin MR, Rosenblatt J, Ghobrial IM, Schlossman RL, Avigan D, Raje N, Munshi NC, Anderson KC, Richardson PG. Management of relapsed and relapsed/refractory multiple myeloma. J Natl Compr Canc Netw. 2011,9,1209-1216.

61. Grabia S, Smyczynska U, Pagacz K, Fendler W. NormiRazor: tool applying GPU-accelerated computing for determination of internal references in microRNA transcription studies. BMC Bioinformatics. $2020,21,425$. 
62. Budczies J, Klauschen F, Sinn BV, Győrffy B, Schmitt WD, Darb-Esfahani S, Denkert C. Cutoff Finder: a comprehensive and straightforward Web application enabling rapid biomarker cutoff optimization. PLoS One. 2012;7(12):e51862. 